PAPER

\title{
Ruptured intracranial aneurysms: the outcome of surgical treatment in experienced hands in the period prior to the advent of endovascular coiling
}

\section{J Lafuente, R S Maurice-Williams}

See Editorial Commentary, p 1605-6

J Neurol Neurosurg Psychiatry 2003;74:1680-1684

See end of article for authors' affiliations

.....................

Correspondence to: $\mathrm{J}$ Lafuente, FRCS, Flat 34 Norfolk House Regency street London SW1P4BD UK; chico@doctors.org.úk

Received

22 November 2002

In final revised form

27 June 2003

Accepted 1 July 2003
Objectives: To evaluate the results of treatment of patients with a ruptured intracranial aneurysm treated by a single experienced vascular neurosurgeon in the period prior to the introduction of endovascular coiling. Methods: Over a mean (SD) period of 9 (2) years, between January 1990 and June 1999, 245 consecutive patients with ruptured intracranial aneurysms were treated. Patients' details were obtained from a database that had been constructed prospectively. The patients consisted of all those patients treated by the senior author (Mr Maurice-Williams) over this period-that is, every third day on call at his unit. During this period, all patients under the age of 75 years with a diagnosis of subarachnoid haemorrhage were admitted to the neurosurgical unit as soon as was practicable regardless of clinical grade. Results: Of 245 patients, 190 (77.6\%) underwent treatment by open surgery using standard microsurgical techniques. At 1 year, the mortality of the operated patients was $2.6 \%$, while $89.5 \%$ of the patients had a Glasgow Outcome Score (GOS) of 4 and 5. The overall management outcome (all patients treated, including operated and non-operated cases) at 1 year was: $17.1 \%$ dead while $74.3 \%$ had GOS 4 and 5 . Of the 190 patients who underwent surgery, 38 (20\%) required additional operations, totalling 72 operations in all. Of these, 32 were for hydrocephalus and 17 for the evacuation of intracranial haematomas/collections. Complications of surgery occurred in 56 patients (29.5\%).

Conclusion: Open surgery, despite good eventual results, is associated with a significant rate of reoperations and complications that would probably be largely avoided with endovascular treatment. Nevertheless, although endovascular coiling has these immediate advantages over surgery it is still not certain that the long term results will be superior to surgery which leads to permanent obliteration of the aneurysm. There may still be a need for open surgery in the future.
$\mathrm{R}$ upture of an intracranial aneurysm is one of the most common neurosurgical emergencies, with an incidence of approximately 6-10 in 100000 persons per year. ${ }^{12}$

Despite major advances in the understanding and treatment of this condition over the last 30 years, the prognosis remains poor, with an overall mortality of $30 \%$ or more, and less than $50 \%$ of patients making a full functional recovery. ${ }^{3-5}$

Until recently, the preferred method of treatment was surgical clipping of the neck of the aneurysm. However, over the last 10 years, surgery has been increasingly replaced by endovascular methods of obliteration of the aneurysm sac. In the UK at least, this process will probably be accelerated by the recently published results of the International Subarachnoid Aneurysm Trial (ISAT). ${ }^{6}$ If the use of open surgery declines, there will be a fall in the number of surgeons with the appropriate skills and experience for this type of specialised and complex surgery. It seemed to us that this might be an appropriate time to review the results of surgical treatment in the hands of what might be considered a fairly typical aneurysm surgeon who had passed through the initial learning curve.

\section{MATERIALS AND METHODS}

We report the treatment and surgical outcome in 245 consecutive patients with ruptured intracranial aneurysms who were admitted under the care of the senior author ( $\mathrm{Mr}$ Maurice-Williams) over a period of $91 / 2$ years from 1 January 1990 to 30 June 1999. These patients were all treated at the Regional Neurosurgical Unit at the Royal Free Hospital and represent about a third of all the cases treated at that Unit over that period of time. There was no selection of cases in their assignment to this series; R S M-W took only the cases that were referred during his on call period-that is, every third day on average.

Endovascular treatment began as a standard method of treatment at the end of the period of study, although a handful of cases had been treated before then.

\section{Admissions policy}

Over the period of the study, an "open door" admissions policy was followed-that is, all patients under the age of 75 years who were referred with a diagnosis of subarachnoid haemorrhage were admitted as soon as practicable after referral, regardless of the patient's clinical grade.

\section{Timing of investigation and treatment}

Patients underwent diagnostic four vessel angiography as soon as was practicable after admission. Serial computed tomography (CT) scanning was employed to monitor such events as hydrocephalus and delayed ischaemia.

Patients with acute hydrocephalus depressing consciousness were treated by immediate external ventricular drainage or ventriculoperitoneal shunting. Definitive treatment of the aneurysm was normally delayed for 9-10 days or more from the presenting haemorrhage-that is, until the initial period of possible vascular instability (vasospasm) had subsided. This was the standard policy for patients in good condition

Abbreviations: CT, computed tomography; GOS, Glasgow Outcome Score 
(Hunt and Hess grades 1-2). ${ }^{7}$ For patients who were obtunded or whose clinical condition was unstable, surgery was delayed until the patient was alert and clinically stable, a process that might take more than 10 days. A handful of patients underwent early surgery either because of the presence of an intracerebral haematoma causing progressive mass effect or because there had been two confirmed bleeds in close succession, indicating that the aneurysm was especially unstable.

\section{Preoperative management}

All patients received nimodipine and a high fluid intake (at least 3 litres over a period of 24 hours) from the time of admission, in an attempt to minimise the risk of delayed cerebral ischaemia. For the same reasons, antihypertensive drugs were not given unless the patient had been on such drugs prior to the ictus. Regular measurement of the urea and electrolytes and haematocrit were carried out. CT scanning was performed on admission and if there was any change in the patient's clinical status. Patients were confined to bed until surgery but were provided with TED ${ }^{\circledR}$ stockings and received regular leg exercises from the physiotherapists. Anticoagulant therapy was not employed prior to surgery.

\section{Surgical management}

All surgery was performed by R S M-W who, at the time the study commenced, had been performing independent aneurysm surgery for over 13 years and had already clipped almost 400 ruptured aneurysms. All operations were performed using the operating microscope and using standard microsurgical techniques. Brain retraction was carried out using a Yasargil type brain retractor, and spring release aneurysm clips of the Sugita or Yasargil type were employed. In a handful of cases where clipping of the aneurysm neck was judged to be unsafe or impracticable, treatment was by proximal arterial occlusion or investment of the aneurysm sac with muslin.

Anterior circulation aneurysms were exposed by standard pterional flaps. Posterior circular aneurysms were exposed by either pterional or subtemporal flaps for aneurysms at the basilar bifurcation or by suboccipital craniectomy in the semi-sitting position for aneurysms arising from the vertebral artery. The dissection and clipping of the aneurysm was performed under controlled hypotension (usually to a level of 70-90 mm Hg systolic blood pressure) while the patient was kept hypervolaemic. Temporary arterial clips across proximal vessels were not normally used. Prior to closure, the wounds were irrigated with antibiotic solution (flucloxacillin and gentamicin), and parenteral antibiotics were commenced at the time of induction of anaesthesia and maintained for 24 hours thereafter.

\section{Postoperative management}

Check angiography was performed at approximately 2-4 days after surgery. If satisfactory, aneurysm occlusion was confirmed, and if the patient's condition was satisfactory, they were then mobilised and parenteral fluids were discontinued. Nimodipine was continued for 21 days from the time of the presenting haemorrhage. Prophylactic anticonvulsant medication (phenobarbitone) was given from the time of surgery and if the patient remained seizure free was continued for 2 weeks, or for 6 months in the case of aneurysms of the middle cerebral artery.

\section{Data collection}

In addition to the regular hospital notes and typed inpatient summary, a separate datasheet was kept for each patient and was completed prospectively by R S M-W during the patient's stay in hospital. These datasheets recorded the patient's
Table 1 Grades of patients (Hunt \& Hess) ${ }^{7}$ at time of admission and at time of surgery

\begin{tabular}{llllll}
\hline & \multicolumn{2}{l}{ At admission } & & \multicolumn{2}{l}{ At time of surgery } \\
\cline { 2 - 3 } \cline { 5 - 5 } Grade & $\mathbf{n}$ & $\%$ & & $\mathbf{n}$ \\
\hline 1 & 64 & 26.1 & & 139 & 73.1 \\
2 & 73 & 29.8 & & 18 & 9.5 \\
3 & 61 & 24.9 & & 25 & 13.2 \\
4 & 34 & 13.9 & & 8 & 4.2 \\
5 & 13 & 5.3 & & 0 & 0 \\
Total & 245 & 100 & 190 & 100 \\
\hline
\end{tabular}

condition on admission, their clinical course, and the detailed results of any investigations and treatment. Key data were entered on running datasheets prospectively. Clinical grading was according to the Hunt and Hess Scale (table 1) ${ }^{7}$ and outcome at 1 year was assessed by to the Glasgow Outcome Score (GOS). ${ }^{23}$ Most patients were assessed by R S M-W in his follow up clinic, except for a handful of patients who had moved away, where follow up was by letter to the patient or the general practitioner. No patient was lost to follow up at 1 year.

\section{RESULTS}

\section{Time to admission}

Despite the "open door" admissions policy, only $61 \%$ of patients arrived within the first 24 hours of the ictus and only $75 \%$ within the first 72 hours of the presenting bleed. Most of the patients who arrived late had had very minor presenting bleeds that had led to delay in diagnosis either by the general practitioner or at the referring district hospital.

\section{Patient characteristics}

Of the 245 patients with ruptured intracranial aneurysms admitted to the neurosurgical unit, 149 were female and 96 were male. Ages ranged between 17 and 75 years, with a mean of 50.3 years. Table 1 shows the clinical grades at the time of admission and just prior to operation. As might be expected, the preoperative grades were considerably improved compared with the grades at admission. This partly reflects the fact that some patients were judged unfit for surgery, whereas other patients would have improved while waiting for surgery. Some poor grade patients would have deteriorated and died.

The sites of the aneurysm were as might have been expected from other series, with $3.6 \%$ situated on the posterior circulation. Seventeen patients $(9.5 \%)$ had more than one aneurysm demonstrated on angiography. In all cases, it was possible to identify the aneurysm that had bled

Table 2 Additional operations (72 operations in 38 patients)

\begin{tabular}{|c|c|c|c|}
\hline \multicolumn{2}{|l|}{ Cranial (68) } & \multicolumn{2}{|l|}{ Non-cranial (4) } \\
\hline $\begin{array}{l}\text { Operations for } \\
\text { hydrocephalus }\end{array}$ & 32 & $\begin{array}{l}\text { Removal of pulmonary } \\
\text { embolus }\end{array}$ & 1 \\
\hline $\begin{array}{l}\text { Evacuation of } \\
\text { haematomas/ } \\
\text { collections }\end{array}$ & 17 & Caesarian section & 1 \\
\hline $\begin{array}{l}\text { Internal decompression } \\
\text { of brain }\end{array}$ & 3 & $\begin{array}{l}\text { Laparotomy for ruptured } \\
\text { duodenal ulcer }\end{array}$ & 1 \\
\hline $\begin{array}{l}\text { Re-exploration of } \\
\text { craniotomy }\end{array}$ & 3 & $\begin{array}{l}\text { Internal fixation of } \\
\text { femoral fracture }\end{array}$ & 1 \\
\hline Removal of bone flap & 8 & & \\
\hline Cranioplasty & 5 & & \\
\hline
\end{tabular}


on clinical angiograpy or CT scans. Table 2 shows the aneurysms that had bled according to site.

One hundred and ninety patients $(77.6 \%$ of the total) underwent surgery for the ruptured aneurysm. In 187 cases the aneurysm was clipped; in three patients the aneurysm was wrapped. No patient received endovascular treatment.

\section{Timing of surgery}

Ninety percent of the operations were performed from day 9 onwards. Eighteen patients underwent earlier surgery, almost all of these being because the aneurysm was associated with an intracerebral haematoma causing mass effect, or because the patient had had two confirmed bleeds in quick succession yet remained in a good clinical grade.

\section{Results of treatment}

The outcome at 1 year of the operated patients according to GOS is shown in table 3; surgical mortality was $2.6 \%$ whereas $83.7 \%$ had made a good recovery (grade 5 of GOS) - that is, the patient was leading a normal life but might have minor neurological or psychological deficits. Taking grades 4 and 5 together, this figure rises to $89.5 \%$, although we do not regard the commonplace practice of regarding patients in both grades 4 and 5 as having a good outcome as satisfactory, because many of the patients in grade 4 who are independent as regards the activities of daily life have major neurological deficits.

\section{Postoperative deaths}

The 1 year mortality of the 190 operated patients was $2.6 \%$ (five deaths). Four patients $(2.1 \%)$ died within 30 days of operation. Of the five postoperative deaths, one died from a pulmonary embolus while in three cases there had been technical problems with the operation. Thus, one patient with a giant basilar aneurysm treated under deep hypothermia died from uncontrollable bleeding when the anticoagulant treatment was reversed. One patient died from cerebral ischaemia caused by inadvertent occlusion of a normal cerebral artery by the clip while in another case postoperative torsion of a clip led to bleeding from the neck of the aneurysm. One patient died from a recurrent haemorrhage several months after having had his aneurysm wrapped.

\section{Complications of surgery}

Fifty seven complications occurred in 56 patients (29.5\%). These are shown in table 4, where they are divided into cranial and systemic complications. The principal surgical complications were cerebral ischaemia (22 cases) and intracranial bleeding or collections (11 cases). Five patients had epileptic fits and four patients had superficial wound infections. The principal systemic complications were chest infections, urinary tract infections, and deep venous thromboses.

\section{Additional operations}

Of the 190 patients who underwent surgery for an aneurysm, $38(20 \%)$ required 72 additional operations during their stay

\begin{tabular}{lcc}
\multicolumn{3}{l}{ Table 3 Outcome results at 1 year } \\
\hline Glasgow Outcome Score ${ }^{23}$ & Operated patients & All patients \\
\hline Good recovery & $159(83.7)$ & $165(67.4 \%)$ \\
Moderate disability & $11(5.8 \%)$ & $17(6.9 \%)$ \\
Severe disability & $15(7.9 \%)$ & $21(8.6 \%)$ \\
Persistent vegetative state & $0(0)$ & $0(0)$ \\
Deaths & $5(2.6 \%)$ & $42(17.1 \%)$ \\
Total & $190(100 \%)$ & $245(100 \%)$ \\
\hline
\end{tabular}

Table 4 Complications of surgery in 56 patients (29.5\%)

\begin{tabular}{lrll}
\hline Cranial complications & \multicolumn{3}{l}{ Non-cranial complications } \\
\hline Infection & 4 & Pulmonary embolism & 1 \\
Post-operative haematoma/ & 11 & Hyponatraemia & 1 \\
collections & 5 & Chest infection & 4 \\
Seizures & 22 & Urinary infection & 3 \\
Infarct/vasospasm & 2 & Myocardial infarction & 1 \\
Cranial nerve palsy & Venous thromboses & 2 \\
& & Fracture: neck of femur & 1 \\
\hline & & \\
\hline
\end{tabular}

in the neurosurgical unit. Thirty two of these operations were for hydrocephalus either before or after the operation to the aneurysm and 17 were for evacuation of postoperative intracranial haematomas or collections, of which 14 were extracerebral (extradural or subdural) and 3 were intracerebral (table 2).

\section{Management outcome}

The overall management outcome of the 245 patients with a ruptured aneurysm is shown in table 4 . The cause of the 42 deaths $(17.1 \%)$ that occurred by 1 year is as follows. Five of these patients died after surgery (see above) and 37 of the patients never had an operation. Of these 37 patients, 10 died from the effects of primary haemorrhage and 3 from non-haemorrhagic deterioration. Twenty four patients died from rebleeds but of these 15 were in a state where they would have been judged unfit for early surgery (grades 4 or 5). Of the remaining nine patients who were in a good clinical condition (Hunt and Hess grade 1-3 at the time of the fatal rebleed), five patients died so soon after their arrival at the neurosurgical unit that early investigation and surgery could not have been carried out prior to the rebleed even had that been the policy of the unit. This left four patients in a good condition who died from recurrent haemorrhage while they were waiting for the "safe period" for surgery.

\section{DISCUSSION}

Although clipping of a ruptured intracranial aneurysm has long been regarded as the gold standard in the treatment of this condition, a new mode of treatment, namely endovascular coiling of the aneurysm, has been increasingly employed since the second half of the 1990s. The recent ISAT trial was set up in Oxford, UK to compare the results of clipping versus coiling for the treatment of ruptured intracranial aneurysm. Recently, the trial was interrupted when it became apparent that the results of coiling might be superior to those of clipping, at least in the short term. ${ }^{6}$ Although there have been criticisms of the trial, and although the impact of the trial has not to date been uniform throughout the world, it seems likely that in the UK at least there will be a further fall in the number of aneurysms subjected to open surgical treatment. One result of this will be the general loss of the specialised surgical skills involved in aneurysm surgery, which at one time constituted a large part of major neurosurgery. A dilution of skills was already becoming apparent in the UK before the results of the ISAT trial, as coiling became more widespread and cases were spread over a larger number of surgeons. At the same time as this was occurring, the number of surgeons with very considerable experience in the field was falling as they retired, died, or withdrew early from this somewhat stressful form of surgery. Already one of the criticisms of the ISAT trial has been that the surgical group was spread among many 
centres and many surgeons, and may not have represented the best that surgery could offer.

This seemed an opportune time to review the sort of results that might be achieved by what might be called an average experienced aneurysm surgeon in the period before coiling appeared. We make no claim that the results we present are in any way different from or superior to those obtained by the generality of experienced surgeons throughout the world who had available to them the appropriate radiological and surgical facilities.

The reported results of aneurysm surgery vary widely, with an operative mortality from $3 \%$ to $36 \% .^{3}{ }^{3}$ s-10 $^{8}$ Comparisons between different series are difficult because of variations in the case mix. The key variables affecting surgical outcome other than the skill and experience of the surgeon concerned are the condition of the patient at the time of surgery and the interval that has passed from the ictus to the operation. ${ }^{4}{ }^{11} 12$

The optimum timing of surgical intervention remains a matter for controversy, although positions have shifted with time. Thirty years ago it was regarded as axiomatic that surgery should be postponed for 10 days or more after the ictus. ${ }^{513}$ Since then, there has been a clear trend towards immediate or early surgery, at least for patients in the best clinical grades and more recently even for those in a less good condition as well, ${ }^{14}$ even though no randomised or controlled trial has shown that early surgery leads to a better overall outcome than delayed surgery.

R S M-W has remained in that minority of surgeons who have adhered to the policy of delayed surgery. This has led to a low postoperative mortality $(2.1 \%$ at 30 days, $2.6 \%$ at 1 year for all patients, including all grades). On the other hand, he has found that approximately $3-4 \%$ of patients of grade $1-3$ will die from theoretically preventable rebleeds while waiting for the safe period. ${ }^{13}$ He believes that this figure would be counterbalanced by an increase in mortality if he had performed early surgery. Indeed, his occasional attempts at early operation in selected patients has led to unsatisfactory results, although it has to be said that this appears to be at variance with the experience of many of his colleagues.

By the time of this present series, R S M-W had already operated on almost 400 intracranial aneurysms and his surgical experience may be said to have passed the initial learning curve and to have reached a stable plateau. In addition, the present series covered a period of stability. The techniques of modern aneurysm management and operative surgery were well established and were not undergoing any significant change during this period. The principal advances had been the introduction of the operating microscope and spring release clips in the late 1960s and early 1970s, and subsequent treatment designed to minimise the risk of delayed ischaemia in the form of deliberate preoperative hypervolaemia and the use of the calcium blocking agent nimodipine. ${ }^{15-17}$

We report a 1 year surgical mortality of $2.6 \%$, with $83.7 \%$ of operated patients in GOS 5 and $89.5 \%$ in GOS 4 and 5 together. These results are comparable with other surgical series with a similar case mix.4691018

The overall management figures at 1 year were a mortality of $17.1 \%, 67.4 \%$ in GOS 5, and $74.3 \%$ in GOS 4 and 5 together. However, these management results do not represent the whole picture, as many additional patients would have died before transfer to the neurosurgical unit, and the delays in transfer would have had the effect of lowering the management mortality.

As stated above, at the present time the preliminary results of the ISAT trial suggest that endovascular coiling gives rise to immediate results that are superior to surgery for the majority of aneurysms. ${ }^{6}$ Quite apart from this, there are clear advantages to coiling, such as a shorter hospital stay, the avoidance of open surgical manipulation of the brain, and the absence of postoperative epilepsy. In our present series, although the surgical and management results may be regarded as satisfactory, complications occurred in $29.4 \%$ of patients, and 38 patients (20\%) required surgery in addition to the aneurysm operation. Although the great majority of patients recovered from these complications and from these additional procedures, it is likely that coiling will eliminate most such complications and additional operations, although there will of course still be patients who require treatment for hydrocephalus. ${ }^{10} 1319$

Nevertheless, it is by no means certain that long term outcome of coiling will be as satisfactory as successful clipping of an aneurysm. If a ruptured aneurysm can be fully clipped as confirmed by postoperative angiography, then the condition may be regarded as cured and the long term risk recurrence of the aneurysm is negligible. The same does not apply to coiling. Reformation of the sac and further bleeding is known to occur in a handful of cases at least in the short term even if a sac appears to have been completely occluded at the time of initial coiling. ${ }^{60-22}$ The longer term risk of recurrence after coiling is simply not known.

Thus, although the use of aneurysm surgery may decrease in the short term, it is possible that it will experience a renaissance at some time in the future. This being so, it seemed to us to be an appropriate time to review the results of routine aneurysm surgery in terms of both mortality and morbidity in what might be regarded as average experienced hands.

\section{Authors' affiliations}

J Lafuente, R S Maurice-Williams, Royal Free Hospital and School of Medicine, Pond Street, Hampstead, London NW3 2QG, UK

Competing interest: none

\section{REFERENCES}

1 Investigators TISoUIA. Unruptured intracranial aneurysms-risk of rupture and risks of surgical intervention. International Study of Unruptured Intracranial Aneurysms Investigators. N Engl J Med 1998;339:1725-33.

2 Linn FH, Rinkel GJ, Algra A, et al. Incidence of subarachnoid hemorrhage: role of region, year, and rate of computed tomography: a meta-analysis. Stroke 1996;276:25-9.

3 Adams HP, Kassell NF, Torner JC, et al. Early management of aneurysmal subarachnoid hemorrhage. A report of the Cooperative Aneurysm Study. J Neurosurg 1981;54:141-5.

4 Kassell NF, Torner JC, Jane JA, et al. The International Cooperative Study on the Timing of Aneurysm Surgery. Part 2: Surgical results. J Neurosurg 1990;73:37-47.

5 Adams $C B$, Loach $A B, O^{\prime}$ Laoire $S A$. Intracranial aneurysms: analysis of results of microneurosurgery. Br Med J 1976;2:607-9.

6 International Subarachnoid Aneurysm Trial (ISAT) collaborative group. International Subarachnoid Aneurysm Trial (ISAT) of neurosurgical clipping versus endovascular coiling in 2143 patients with ruptured intracranial aneurysms: A randomized trial. Lancet 2002;360:1267-74.

7 Hunt WE, Hess RM. Surgical risk as related to time of intervention in the repair of intracranial aneurysms. J Neurosurg 1968;28:14-20.

8 Kassell NF, Torner JC, Haley EC, Jr, et al. The International Cooperative Study on the Timing of Aneurysm Surgery. Part 1: Overall management results. J Neurosurg 1990;73:18-36.

9 Auer LM. Unfavorable outcome following early surgical repair of ruptured cerebral aneurysms - a critical review of 238 patients. Surg Neurol 1991;35:152-8.

10 Leber KA, Klein GE, Trummer M, et al. Intracranial aneurysms: a review of endovascular and surgical treatment in 248 patients. Minim Invasive Neurosurg 1998;41:81-5.

11 Maurice-Williams RS, Kitchen ND. Ruptured intracranial aneurysmslearning from experience. Br J Neurosurg 1994;8:519-27.

12 Maurice-Williams RS, Marsh $\mathrm{H}$. Ruptured intracranial aneurysms: the overall effect of treatment and the influence of patient selection and data presentation on the reported outcome. J Neurol Neurosurg Psychiatry 1985;48:1208-12.

13 Maurice-Williams RS, Wadley JP. Delayed surgery for ruptured intracranial aneurysms: a reappraisal. Br J Neurosurg 1997;11:104-9.

14 Koivisto T, Vanninen R, et al. Outcomes of early endovascular versus surgical treatment of ruptured cerebral aneurysms. A prospective randomized study. Stroke 2000;31:2369-77.

15 Solomon RA FM, Lennihan L. Early aneurysm surgery and prophylactic hypervolemic hypertensive therapy for the treatment of aneurysmal subarachnoid hemorrhage. Neurosurgery 1988;23:669-74. 
16 Pickard JD, Murray GD, Illingworth R, et al. Effect of oral nimodipine on cerebral infarction and outcome after subarachnoid haemorrhage: British aneurysm nimodipine trial. BMJ 1989;298:636-42.

17 Corsten L, Raja A, et al. Contemporary management of subarachnoid hemorrhage and vasospasm: the UIC experience. Surg Neurol 2001:56:140-8.

18 Haley EC, Jr, Kassell NF, Torner JC. he International Cooperative Study on the Timing of Aneurysm Surgery. The North American experience. Stroke 1992;23:205-14.

19 Solander S, Ulhoa A, Vinuela F, et al. Endovascular treatment of multiple intracranial aneurysms by using Guglielmi detachable coils. J Neurosurg 1999;90:857-64.
20 Conrad MD, Pelissou-Guyotat I, Morel C, et al. Regrowth of residual ruptured aneurysms treated by Guglielmi's Detachable Coils which demanded further treatment by surgical clipping: report of 7 cases and review of the literature. Acta Neurochir (Wien) 2002;144:419-26.

21 Thornton J, Debrun GM, et al. Follow-up angiography of intracranial aneurysms treated with endovascular placement of Guglielmi detachable coils. Neurosurgery 2002;50:239-49.

22 Birchall D, Khangure MS, et al. Delayed aneurysm rerupture following total endovascular occlusion. Br J Neurosurg 2001;15:269-72.

23 Jennett B, Bond $M$. Assessment of outcome after severe brain damage. Lancet $1975 ; 1: 480-4$.

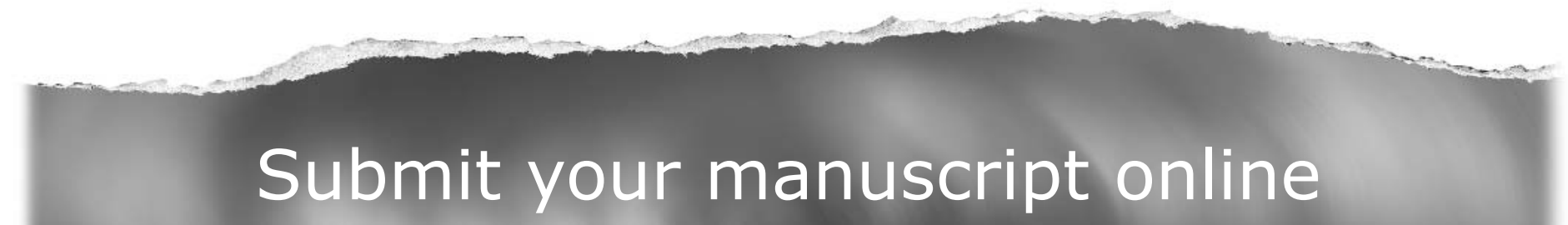

\section{Bench $>$ Press}

Click on 'submit/review a manuscript online' on our homepage to access Bench $>$ Press, our online submission and review system. Bench>Press enables the full peer review process to be conducted entirely online.

www.jnnp.com 